\title{
IMPACT OF WORKFORCE DIVERSITY ON ORGANIZATIONAL CULTURE: A CASE OF UNIVERSITIES OF PAKISTAN
}

\section{Aurangzeb ${ }^{1}$, Kamleshwer Lohana ${ }^{2}$, Nazia Bibi ${ }^{3}$, Ishtiaq ur Rehman ${ }^{4 *}$, Shahida Habib Alizai ${ }^{5}$}

${ }^{1}$ Professor, Dean of Management Sciences, Preston University, Kohat, Pakistan; ${ }^{2}$ Assistant Professor, Mehran University Institute of Science, Technology, and Development (MUISTD), Pakistan; ${ }^{3} \mathrm{Ph} . \mathrm{D} .$, Scholar (Economics), International Islamic University Islamabad, Pakistan; ${ }^{4 *} \mathrm{Ph}$.D., Scholar (Finance), Qurtaba University D.I. Khan, Pakistan; ${ }^{5}$ Assistant Professor, Gender Development Studies Department, University of Balochistan, Pakistan.

Email: "mahboobmails@gmail.com

\section{Article History: Received on $5^{\text {th }}$ May 2021, Revised on $19^{\text {th }}$ May 2021, Published on $19^{\text {th }}$ May 2021}

\begin{abstract}
Purpose of the Study: The present research was undertaken to determine the impact of workforce diversity taxonomy like diversity climate, value, organizational justice, and identity on various dimensions of organizational culture.

Methodology: A sample of 117 university teachers selected from the university and higher educational institutions in Pakistan. Convenient sampling techniques were used to collect the data through a Google survey, using workforce diversity.

taxonomy inventory and organizational culture questionnaire. Data analyzed by using a t-test to compare the mean scores of various dichotomized groups to see the effect of workforce diversity taxonomy on organizational culture with the help of the SPSS package.

Principal Findings: Results revealed that workforce diversity taxonomy like diversity climate, value, organizational justice, and identity significantly influenced organizational culture and its various dimensions. Perceived high and low respondents' workforce diversity taxonomy differed significantly on organizational culture.
\end{abstract}

Applications of the study: This study can formulate strategies to improve workforce diversity in universities and higher educational institutions in emerging economies like Pakistan.

Novelty/Originality of this study: The present research contributes to the literature on perceived workforce diversity taxonomy and organizational culture in terms of autonomy, trust, communication, transparency, interpersonal relation, decision making, and overall organizational culture, particularly in university and higher educational institution's teachers.

Keywords: Organizational Culture, Workforce Diversity, Diversity Climate, Value, Organizational Justice, Identity.

\section{INTRODUCTION}

The present research work targeted the universities and higher educational institutions that most recurrently demonstrate a high employee diversity degree. "Workplace diversity is increasing internationally and is increasingly important to organizational success" (Taylor, 2011); human resource diversity, where enhances the innovation and creativity in the individuals and teams, subsequently entice great attention and challenges for the managers and organizations. Thus, managing the workforce diversity arises as an integral approach in organizations, especially in the universities and higher educational institutions, where workforce diversity is very high. Therefore, a vital need to institutionalize the workforce diversity for improved performances and efficiency within the people acquired from a diverse group of different backgrounds. For doing so, organizational culture could be another important key factor in any organization if it has a firmly held and widely shared set of beliefs supported by its strategies and structure. Regardless of any industry, organizational culture is an essential tool for effective management practices and attaining its objectives successfully (Betaken et al., 2010), especially for managing diverse human resources.

Workforce diversity in corporations improves the employees' performances and enhanced learning opportunities and growth. Diversity generally considers the difference in age, sex, experience, education, nationality, race, and other disabilities. Van Knippenberg and Shippers (2007) argued that effectively managed workforce results could be visualized as the comprehensive growth of the organizational members' competitiveness among the people, improved work performance, innovativeness, and creative workplace. Thomas (1999) defines diversity as "those individual differences that are socially and historically significant and which have resulted in differences in power and privilege inside as well as outside of organizations." Hashim, Ullah, and Khan, (2017) highlighted the two different perspectives as "Workforce diversity refers to the division of the workforce into distinct categories that (a) have a perceived commonality within a given cultural or national context and that (b) impact potentially harmful or beneficial employment outcomes such as job opportunities, treatment in the workplace, and promotion prospects-irrespective of job-related skills and qualifications". $\underline{\operatorname{Cox}(1994)}$ defined, "Cultural diversity means the representation, in one social system, for people with distinctly different group affiliations of cultural significance."

A consistent and observable pattern of behaviour within the organizations, a one-line statement describing the term 'organizational culture', comprises several challenges and complexities. Organizational culture is a dynamic, 
contextual, and having multi-faceted term, 'it cannot be easily judged as good/bad, strong/weak, or effective/ineffective' (Schein, 2004). academic literature revealed numerous definitions of organizational culture and classified its dimensions with various evaluation models. Organizational culture is the shared perceptions of organizational practices. It can be viewed as a collective approach to developing the norms within the organization to regulate the employees' behaviour and functions for the attainment of organizational goals. A comprehensive definition beyond artifacts and behaviours of culture is a pattern of shared basic assumptions that a group learned as it solved its problems of external adaptation and internal integration, that has worked well enough to be considered valid and, therefore, to be taught to new members as the correct way to perceive, think, and feel to those problems' (Khan \& Ullah, 2021). Some of the authors highlight the other faceted of the organizational culture as; Martins and Terblanche (2003) defined "organizational culture as the set of subconscious values and beliefs deeply seated in the organizational structure and shared by its members". Organizational culture is the setting to develop uniformity and efficiency in the workplace (Fralinger \& Olson, 2007), and holds the organization together, and stimulates employees to think, behave and perform (Wilderom et al. 2001).

\section{RESEARCH OBJECTIVES}

The present research intended to explore the effect of workforce diversity taxonomy on organizational culture in a challenging educational environment among the University teachers of Pakistan. It aims to compare the high and low effects of diversity climate, value, organizational justice, and identity on all factors of organizational culture.

\section{REVIEW OF LITERATURE}

The interrelationship between employee workforce diversity and organizational culture attracts many researchers and academicians to target the diverse industrial sector. Furthermore, the internationalization of the business and human resources creates opportunities and challenges for the organizations to utilize and manage the resources within the set boundaries of the organizational culture. Therefore, in this section of the study, an attempt has been made to explore and investigate the previous studies focused on the interrelationship of employee workforce diversity and organizational culture in Universities and Higher education institutions worldwide.

The literature on workforce diversity highlighted the impact on various dimensions like a significant impact on organizational performance (Richard et al. 2013; Chin and Huam, 2015; Cho et al. 2017), innovation orientation; (Talke et al. 2011), productivity; (Ali, 2016), and promotion of employees (Roman, 2017). In addition, several studies highlight the gender diversity practices of many universities, such as Vermeulen (2010) highlight diversity management for higher education institutions of South Africa and Germany. Meric et al. (2015) discussed and analyzed higher education institutions in the United States of America. Vázquez \& Elston (2006) highlighted the academic career trajectories with particular reference to Spain.

Many organizations witnessed significant improvement in the workplace environment, motivating and efficient employees, and retaining key employees, with the successful implementation of diversity management (Ullah, Malik, Zeb, Rehman, 2019). Other influences in the form of employees' perception of marginalization and organizational efficiency resulted from managing diversity and teamwork (Ullah, Afghan, \& Afridi, 2019). Green et al. (2015) highlight the benefits of diversity in adaptability, alternative solutions for problems, availability of various services, variety of skills, and expertise. Hashim, Ullah, Khan (2017) inferred the perception of gender diversity in the organization for the significant positive impact on employees' performance. Hashim, Ullah, Khan (2017) found the diversity in the workforce and institutional effectiveness statistically significant.

Universities and higher educational institutions have observed a high pressure to respond to globalization and international competition and adapt to the changing internal and external environmental factors (Beytekin et al. 2010). In response to the situations, organizational culture in terms of universities' educational process and administrative authorities is acknowledged as an important factor in harmonizing integrated approach in response to global expectations (Bartell, 2003). Thus, a strong organizational culture values on 'mission, leadership, information, strategy and socialization' of university influenced the individual and institutions performance (Taye et al. 2019)

\section{HYPOTHESES}

To achieving the research objective the following hypotheses are formulated.

$\mathbf{H}_{\mathbf{0}_{1}}$ : There would not be a significant effect of diversity climate on organizational culture and its dimensions.

$\mathbf{H}_{\mathbf{0} 2}$ : There would not be a significant impact of value on organizational culture and its factors.

$\mathbf{H}_{\mathbf{0} 3}$ : There would not be a significant effect of organizational justice on organizational culture and its facets.

$\mathbf{H}_{\mathbf{0}}$ : There would not be a significant effect of identity on organizational culture and its factors.

\section{RESEARCH METHODOLOGY}

The present study sample consists of 117 faculty members working in different government and private universities and higher educational institutions in Pakistan. The questionnaire link was distributed through electronic means among the respondents through E-mails and other social media platforms. The respondents were assured that the privacy of 
information would be treated as highly confidential, and the collected information will be used only for academic purposes. A descriptive research design model has been used to investigate workforce diversity taxonomy on organizational culture and its various factors.

Organizational Culture Questionnaire, modified by Reddy (2002), has been used to collect the data from the respondents for analyzing organizational culture. The original questionnaire consists of 12 dimensions with fifty-nine items. In the current research, six dimensions as autonomy, trust, communication, transparency, interpersonal relations, and decision making comprised of 30 items used, and each item responded on a 5-point Likert scale on a continuum of strongly agree to disagree with a weighted score of 1 to 5 strongly, and in the case of negatively phrased question scoring was reversed. In addition, the questionnaire developer's reliability and validity were pretested (Reddy,2002). The respondent's total score on each dimension is considered a single score and a composite of all dimensions representing organizational culture.

To measure employees' perception towards workforce diversity in the organization, the Workforce diversity Inventory developed and standardized by Taylor (2011) has been used to collect the data. Workforce diversity factors such as diversity climate, identity value, and organizational justice were included in the set of questionnaires. Each factor consists of four items, and each item is rated on 5-point Likert scale with a response category of strongly disagree to agree with a weighted score of 1 to 5 strongly. In the case of a negatively phrased question, scoring was reversed. Thus, a higher score on each count of WDI reveals a high perception towards workforce diversity. In addition, the reliability and validity of the scale were determined.

In the present research study, to analyze the data, a t-test was found as a suitable statistical method to compare different groups on relative mean scores of studied variables as organizational culture and its various dimensions. Furthermore, to test the effect of workforce diversity taxonomy, variables were dichotomized to form the groups based on the median of diversity climate, value, organizational justice, and identity. SPSS statistical package used to analyze data.

\section{RESULTS AND DISCUSSION}

Table 1 represents the perceived organizational culture in terms of autonomy, trust, communication, transparency, interpersonal relation, decision making, and overall organizational culture of university teachers as the effect of diversity climate. The obtained scores of high and low groups were compared on each factor of organizational culture. The calculated mean value of employees on autonomy found $\mathrm{M}=19.23$ and $\mathrm{M}=16.18$ for a high and low group of diversity climate with sd. $=2.96$ and 2.78 respectively. Two group of employees differed significantly $(t=.52, p<.01)$ on autonomy. The result interpreted that an organization's success depends largely on the autonomy provided to employees (Kossel \& Sonia, 1993) for effective performance. Diversity climate refers to the perception of relationships among the members of varied groups and organizational norms, policies, practices, and procedures that were directly or indirectly maintaining and eliminating discrimination that influenced the autonomy provided to employees for effective performance in the organizations (Cropanzano, Li \& James, 2007). Perceived high diversity climate scored significantly greater on autonomy dimension of organizational culture than low diversity climate group of employees attributed to enjoying more freedom and acting freely to select their work method and exercise freedom in taking the initiative in the organization. The diversity climate at the workplace facilitates and promotes cultural and social cohesiveness and the transformation of information within the groups (Douglas, 2010).

Table 1 Showing the impact of diversity climate on organizational culture among university teachers $(\mathrm{N}=117)$.

Table 1: Impact of diversity climate on organizational culture among university teachers $(\mathrm{N}=117)$

\begin{tabular}{lcccccc}
\hline Variables & Value & N & Mean & Std. Deviation & t & Sig. Level \\
\hline Autonomy & High Group & 69 & 19.23 & 2.96 & 4.452 & 0 \\
\hline Lrust & Low Group & 48 & 16.81 & 2.78 & & \\
\hline High Group & 69 & 19.34 & 3.33 & 2.145 & 0.034 \\
\hline Communication & Low Group & 48 & 18.04 & 3.09 & & \\
\hline & High Group & 69 & 15.14 & 2.75 & 1.697 & 0.092 \\
\hline Transparancy & Low Group & 48 & 14.31 & 2.38 & & \\
\hline Interpersonal Relation & High Group & 69 & 15.05 & 2.79 & 8.114 & 0 \\
\hline & Low Group & 48 & 19.85 & 2.38 & & \\
\hline Decision Group & 69 & 12.73 & 2.79 & -1.031 & 0.305 \\
\hline & Low Group & 48 & 13.06 & 1.95 & & \\
\hline Overall Culture & High Group & 69 & 20.14 & 2.95 & 9.235 & 0 \\
\hline & Low Group & 48 & 14.45 & 3.69 & & \\
\hline
\end{tabular}


Trust one of the dimensions of organizational culture linked to performance, communication, and cooperation in the organization influenced by diversity climate Trust is associated with honesty and integrity in communication and determines positive relationships (Hofhuis et al., 2016). The mean trust score of high and low diversity climate found 19.34 and 18,04 with sd. 3.33 and 3.09, respectively. The two groups high and low diversity climate compared on trust revealed significant difference $(\mathrm{t}=2.145, \mathrm{p}<.05)$. The positive diversity climate is important for managing workforce diversity plans and affects employees' trust (Rynes and Rosen,1995). Researchers of many disciplines are interested in explaining and managing workforce diversity from a global perspective. Hofhuis et al. (2016) observed a significant positive correlation between diversity climate and trust. A high diversity climate appeared to increase trust; group identification reduces interpersonal conflict and aggression, and miscommunication within group members (DrachZahavy and Trogan 2013; Hofhuis et al. 2012).

The perceived high and low diversity climate groups of employees show a mean score on communication 15.14 and 14.31 with sd. 2.75 and 2.38, respectively. The two groups compared on communication dimension of organizational culture; they did not differ significantly. The result explained that perceived high and low diversity climate did not face language barriers, as instructions issued in the concerned language. However, language fluency and cultural confidence are noticed in diverse work settings. Overall score on communication dimension observed high that revealed strong organizational culture increased employee's commitment at work. To increase strong culture needs open and honest communication in a diverse workplace, which enhances the commitment of employees, especially teachers at universities and colleges.

Two university teachers classified into perceived high diversity climate and low diversity climate than transparency. The mean score of high diversity climate on transparency was observed 15.05 while the low group found 10.85 with sd. 2.79 and 2.69, respectively. The difference between a high and low diversity climate on transparency was significant $(\mathrm{t}$ $=8.11, \mathrm{p}<.001$ ) beyond .01 levels. Perceived high diversity climate scored significantly greater than low diversity group on transparency. The result characterizes by high diversity group members perceives a strong organizational culture filled with values and favouring organizational policies and practices, which increases the higher degree of employee commitment, involvement, and satisfaction and, consequently, leading to organizational effectiveness. On the other hand, the perceived low diversity group scored low on transparency refers to a weak organizational culture that gives fewer values to policies and practices leading low degree of organizational effectiveness. The employee with high diversity climate received regular feedback; they know policies and rules and decisions are transparent. Hofhuis et al. (2016) suggested that employees with a perceived high diversity climate revealed job satisfaction, developed group identification, and shared knowledge with group members. On the other hand, they perceived a low diversity climate not clear about policies, rules, feedback, and decision-making leading to conflict between group members (Hofhuis et al. 2016; Fiske, 1998).

An interpersonal relationship is one of the dimensions of organizational culture that measures the experiences of university teachers in Pakistan as the outcome of perceived high and low diversity climate. Two teachers with perceived high and low diversity compared on interpersonal relations. The obtained mean score on interpersonal relation found 12.79 and 13.06 with sd. 1.88 and 1.29 for perceived high diversity climate and low diversity climate, respectively. The difference between the two groups was not found significant $(\mathrm{t}=1.031)$. The results interpreted that every member established independent relations at the workplace and performed their task, and rarely cooperate with their counterparts; on the other hand, established dependent relationships and requires cooperating to achieve the goals. Indeed, there is a competitive relationship within the group members, and everyone is making an effort to compete with their counterparts. In the university, all faculties cooperate; hence, they developed a mutually cooperative interpersonal relationship and made a joint effort to achieve the university's objectives. Therefore, two groups of university teachers with perceived high diversity climate and low diversity climate did not differ significantly on interpersonal relationships and experiencing similar fate is grounded in interpersonal relationships (Manila, 2007) includes task-related relation involves in exchange of resources and relationship appears mutual association (Khan \& Ullah, 2021).

Results shown in Table1 revealed the influence of perceived high and low diversity climate on decision making. The mean score on decision making of high diversity climate found 20.14 and low diversity climate 14.45 on decision making and standard deviation calculated 2.95 and 3.69 respectively. The two groups of university teachers differ significantly $(\mathrm{t}=9.23, \mathrm{p}<.001)$ on decision making. The perceived high diversity climate comes from different backgrounds with different skills accepted; they are treated fairly with values and dignity contributing to the organizational decision-making process (Gunderson \& Sutcliffe, 2002), leading to effective utilization of skills (PinkHarper et al., 2017). The high diversity climate perceived that they would share in decision-making. In contrast, the low diversity climate group significantly scored low on decision-making, having a different perception of share in decisionmaking (Baan, 2016).

The results shown in Table1 revealed the mean, Sd. for the overall organizational culture of high diversity climate and low diversity climate groups. The mean score on overall organizational culture of perceived high and low diversity climate groups was found 101.67 and 87.5 with standard deviation 11.60 and 10.3, respectively. Compared to organizational culture, the difference was found statistically significant $(\mathrm{t}=6.7, \mathrm{p}<.001)$ beyond .001 levels of significance. Organizational culture is a vital factor of HRM function. The respondents with a perceived high diversity 
climate viewed that existing strong organizational culture may attract the teachers to perform their tasks effectively to achieve the set standard. The results interpreted that an individual cannot create a university culture. Still, it can be developed jointly by accepting the values in creating university culture, adopting a multidimensional approach to teaching and research (Hashmi, Ullah \& Khan, 2017), and focusing on realizing the specific goals. A diverse climate's most significant benefits may form employees' retentions, highly instigate motivation, and a healthy workplace atmosphere (Khan \& Ullah, 2021). Therefore, the proposed hypothesis (H01) was rejected.

Table 2: Impact of value on organizational culture among university teachers $(\mathrm{N}=117)$

\begin{tabular}{llccccc}
\hline Variables & Value & N & Mean & Std. Deviation & t & Sig. Level \\
\hline Autonomy & High Group & 79 & 19.05 & 2.76 & 4.158 & 0 \\
\hline Low Group & 38 & 16.55 & 3.16 & & \\
\hline Trust & High Group & 79 & 19.6 & 3.05 & 3.955 & 0.034 \\
\hline Communication & Low Group & 38 & 17.15 & 3.17 & & \\
\hline & High Group & 79 & 14.96 & 2.68 & 0.963 & 0.092 \\
\hline Transparancy & Low Group & 38 & 14.47 & 2.51 & & \\
\hline Interpersonal Relation & High Group & 79 & 13.96 & 3.44 & 3.06 & 0 \\
\hline & Low Group & 38 & 12.02 & 3.07 & & \\
\hline Decision Making Group & 79 & 12.75 & 1.82 & -1.181 & 0.305 \\
\hline & Low Group & 38 & 13.1 & 1.29 & & \\
\hline Overall Culture & High Group & 79 & 18.82 & 3.91 & 3.73 & 0 \\
\hline & Low Group & 38 & 15.71 & 4.36 & & \\
\hline & High Group & 79 & 99.16 & 12.16 & 4.15 & 0 \\
\hline
\end{tabular}

Table 2 shows the influence of value on various dimensions of organizational culture. In the classification of workforce diversity, value has been identified as one of the dimensions of workforce diversity that influenced the perceptions of preferences, beliefs, and behaviour in a diversified workplace (Taylor, 2011). The perceived high and low value influences organizational culture. This research tried to see the impact of high and low value on different dimensions of organizational culture. The mean score of perceived high value and low value on autonomy was calculated at 19.05 and 16.55 with sd. 2.7 and 3.16, respectively. The mean difference between the two groups on autonomy was significant $(\mathrm{t}=$ $44.15, \mathrm{p}<.01)$. Respondents with high value believe that they enjoy more freedom and autonomy in selecting their own choice of work as compared to their counterparts. Two groups were compared on trust and observed a significant difference $(\mathrm{t}=3.95, \mathrm{p}<.01)$ that perceived high-value respondents significantly more weight to trust that affected organizational culture. The differences in values influence organizational outcomes. The teachers with high value believe that trust based on cooperation and good intention that other teachers' action will be motivated to a strong organizational culture. As far as communication is concerned, perceived high value and low-value subjects did not differ significantly $(t=.96)$, suggesting that communication is either formal or informal meant for sharing information within the organization members. Both the groups perceived good communication in a diversified workforce can contribute to achieving organizational goals (Ullah, Afghan, \& Afraid, 2019) and develop a conducive work environment. The mean score on transparency of perceived high value found 13.96, whereas the mean score of perceived low value found 12.02. Two university teachers in Pakistan did not differ significantly on the transparency count of organizational culture $(t=3.06, \mathrm{p}<.01)$. The perceived high-value section of teachers viewed a high degree of openness in decision-making, appraisal system, and transparency in information sharing compared to their counterparts, leading to developing strong and healthy organizational culture. Interpersonal relation is concerned with no significant difference observed between the two teachers with perceived high value and low value. Respondents were sharing similar attitudes and values towards interpersonal relations. However, perceived low-value teachers put more emphasis on interpersonal relationships than high value. Hence, interpersonal relation is vital for developing healthy organizational culture.

The mean score of perceived high-value respondents on decision making a count of organizational culture found 18.82 with sd. 3.91 whereas a mean score of perceived low vale respondents found 15.71 with sd. 4.36 on decisionmaking count. The two groups of respondents differ significantly in decision making $(\mathrm{t}=3.73, \mathrm{p}<.01)$. The highvalue subjects believe in responsibility, growth, honesty, trust, and commitment affect decision-making. They believe decisions are being made good for the organization leading healthy organizational culture. Since the perceived high value drives their goals and motivates them to set priorities in decision making makes a difference between perceived low-value respondents. The effect of the value observed on overall organizational culture. The mean score on overall organizational culture was observed 99.16 and 89.02 for the perceived high-value group and low group, respectively. The mean difference between a high and low group of teachers was significant beyond .01 
levels of significance. The high group of respondents significantly scored greater than a low group of respondents on organizational culture. Hence differences appeared because of value perception towards the determinants of organizational culture. The proposed null hypothesis (H02) there would not be a significant effect of value on organizational culture was not accepted.

Table 3: Effect of organizational justice on organizational culture among university teachers=117)

\begin{tabular}{|c|c|c|c|c|c|c|}
\hline Variables & Value & $\mathbf{N}$ & Mean & Std. Deviation & $\mathbf{t}$ & Sig. Level \\
\hline \multirow[t]{2}{*}{ Autonomy } & High level & 79 & 19.0506 & 2.76377 & 4.158 & 0.000 \\
\hline & Low Level & 38 & 16.5526 & 3.16823 & & \\
\hline \multirow[t]{2}{*}{ Trust } & High level & 79 & 19.6076 & 3.0568 & 3.955 & 0.000 \\
\hline & Low Level & 39 & 17.1579 & 3.1753 & & \\
\hline \multirow[t]{2}{*}{ Communication } & High level & 79 & 14.962 & 2.68635 & 0.963 & 0.339 \\
\hline & Low Level & 38 & 14.4737 & 2.51199 & & \\
\hline \multirow[t]{2}{*}{ Transparancy } & High level & 79 & 13.962 & 3.4472 & 3.06 & 0.003 \\
\hline & Low Level & 39 & 12.0263 & 3.0799 & & \\
\hline \multirow[t]{2}{*}{ Interpersonal Relation } & High level & 79 & 12.7595 & 1.82022 & -1.181 & 0.24 \\
\hline & Low Level & 38 & 13.1053 & 1.29008 & & \\
\hline \multirow[t]{2}{*}{ Decision Making } & High level & 79 & 18.8228 & 3.91499 & 3.73 & 0.000 \\
\hline & Low Level & 39 & 15.7105 & 4.36762 & & \\
\hline \multirow[t]{2}{*}{ Overall Culture } & High level & 79 & 99.1646 & 12.6071 & 4.15 & 0.000 \\
\hline & Low Level & 38 & 89.0263 & 12.47806 & & \\
\hline
\end{tabular}

Table 3 shows the effect of organizational justice on organizational culture and its factors. Perceived high organizational justice and low organizational justice compared on various autonomy. The mean score of perceived high and low organizational justice on autonomy found 19.06 and 16.65 with sd. 2.79 and 3.11, respectively. The two groups compared on autonomy and result revealed a significant mean difference $(\mathrm{t}=4.11, \mathrm{p}<.001)$. The result interpreted that the group of perceived high organizational justice enjoys significantly greater autonomy than low organizational justice. There was a significant difference observed between high and low perceived organizational justice on trust $(\mathrm{t}=2.30, \mathrm{p}<.05)$. The faculties perceiving high organizational justice, accepting fairness in procedures and policies, and believe that employees are trustworthy create a strong organizational culture. As far as communication is concerned, there was no significant difference observed between the two groups of faculties serving in the universities. Two groups based on high and low organizational justice differ significantly on the transparency dimension of organizational culture. The mean score of perceived high organizational justice and low organizational justice on transparency appears 14.59 and 10.90 with Sd.3.11 and 2.66, respectively. The difference between the high and low organizational justice on transparency was significant $(\mathrm{t}=6.70, \mathrm{p}<001)$. The employees experiencing high organizational justice viewed more transparency in policies and procedures than their counterparts; they believe communication is clear and transparent, leading to solid organizational culture. The mean score of high and low groups of organizational justice on interpersonal relations was found 12.79 and 13.02 with Sd. 1.85 and 1.25, respectively. As far as interpersonal relations are, a low concerned group of organizational justice showed better than a high group of organizational justice. Still, the difference between the two groups did not appear significant. Both groups show favourable and conducive interpersonal relations, leading to a strong organizational culture. Decision-making is one of the important factors of organizational culture, leading to determine strong culture. The perception of high and low groups of organizational justice towards decision making in the university setup develop strong and weak culture. The mean score of perceived high organizational justice and low organizational justice on decision making were found 19.69 and 1.20, whereas Sd. Found 3.10 and 4.00, respectively. Two university teachers differed significantly on decision making $(\mathrm{t}=7.56, \mathrm{p}<.001)$. The results showed the relationship between perceived organizational justice and decision making. Perceived high organizational justice accepts the fairness of procedures in the decision-making process. They are treated with respect and dignity (Greenberg, 1990; Rasta \& Pourebrahimi, 2013) contrary to perceived low organizational justice. Therefore, perceived organizational justice may work as regulating tool for decision-making (Cassar and Buttigieg, 2015). The mean score on overall organizational culture for high organizational justice was 100.49 with sd. 11.65 whereas mean score on overall organizational culture for low organizational justice found 86.97 with sd. 11.09. The two groups in terms of overall organizational culture differed significantly beyond .01 levels of significance $(\mathrm{t}=$ $6.14, \mathrm{p}<.001)$. The faculties who perceived high organizational justice significantly believed more in values, policies, procedures, transparency, decision making, etc. They are contributing to develop a strong organizational culture. Hence organizational justice significantly influenced organizational culture. The proposed null hypothesis (H03) was rejected.

Table 4 shows the results of identity as one factor of workforce diversity described in employees' perception towards an organization that shapes emotions and behaviour (Hogg \& Terry, 2000). The perceived in-group identity 
and out-group identity were compared on autonomy. The mean score of in-groups on autonomy found 18.75 and sd. 3.02 while meaning score of out-group employees found 17.29 and sd. 3.10. The difference between the groups was found $(t=2.44)$ statistically significant at a 0.01 level of significance. The mean score on trust was fond 19.00 with sd. 3.39 for university teachers who perceived in-group members and meant score on trust for the members who perceived out-group found 18.46 with Sd. 3.09. The two groups compared on trust; difference did not appear statistically significant. While a similar feeling was found in both groups. As far as communication is concerned, perceived in-group and out-group did not differ significantly. The mean score of in-group respondents was found 14.06 and sd. 3.18 while meaning score of out-group respondents found 11.97 and sd. 3.51. The respondents of the in-group perceive more transparency than the respondents of the out-group. The difference between the two groups was significant $(\mathrm{t}=3.16)$ beyond .01 levels of significance. In-group faculties perceive a higher degree of openness in decision-making, promotional awareness, and performance appraisal system. In contrast, out-group members perceived less open decision-making and transparency in information sharing. The mean score on decision making of perceived in-group identity was found 19.34 with sd. 3.42, whereas the mean score of perceived out-group respondents were found 14.97 with sd. 4.36 on the same count. The perceived in-group identity and out-group identity differed significantly $(\mathrm{t}=5.54, \mathrm{p}<.001)$. It is interpreted that in-group members viewed that whatever decisions are being made good for the organization and employees and communicated to aware them; and they believe that decisions are important based on problems and issues either by the top-level or joint process, on overall organizational culture perceived in-group identity and out-group identity compared to see the effect of perceived identity.

The observed mean score on organizational culture was 99.07 and 89.92 with SD 11.79 and 13.47 for in-group and outgroup identity. Two respondents were found to differ statistically significant $(t=3.65)$ beyond .01 levels of significance. The result attributed to perceived in-group and out-group forms the behaviour and emotions of respondents at the workplace that determines intra-group and inter-group feelings and relations (Hogg \& Terry, 2000). The perceived ingroup respondents' positive self-worth accounted for strong organizational culture, while out-group respondents viewed exclusion based on an individual's perceived social identity. Perceived inclusion/exclusion is associated with job satisfaction, organizational commitment, and organizational justice (Aquavit et al., 2009; Cho \& Moor Barak, 2008). Identity develops an employee's social bond towards the complete association of the organization leading strong culture. Therefore, the proposed hypothesis (H04) was not accepted.

Table 4: Impact of identity on organizational culture among university teachers $(\mathrm{N}=117)$

\begin{tabular}{llccccc}
\hline Variables & Identity & $\mathbf{N}$ & Mean & Std. Deviation & $\mathbf{t}$ & Sig. Level \\
\hline Autonomy & In-Group & 76 & 18.75 & 3.02049 & 2.443 & 0.017 \\
\hline & Out-Group & 41 & 17.2927 & 3.10841 & & \\
\hline Trust & In-Group & 76 & 19.1 & 3.39804 & 0.865 & 0.389 \\
\hline Oommunication & Out-Group & 41 & 18.4634 & 3.0911 & & \\
\hline & In-Group & 76 & 15.0789 & 2.73136 & 1.618 & 0.109 \\
\hline Out-Group & 41 & 14.2927 & 2.37954 & & \\
\hline Transparancy & In-Group & 76 & 14.0658 & 3.1888 & 3.167 & 0.002 \\
\hline Interpersonal Relation & Out-Group & 41 & 11.9756 & 3.51773 & & \\
\hline In-Group & 76 & 12.8421 & 1.8551 & -0.291 & 0.772 \\
\hline Decision Making & Out-Group & 41 & 12.9268 & 1.2726 & & \\
\hline In-Group & 76 & 19.3421 & 3.42365 & 5.548 & 0 \\
\hline Overall Culture & Out-Group & 41 & 14.9756 & 4.36742 & & \\
\hline & In-Group & 76 & 11.79804 & 11.79804 & 3.658 & 0 \\
\hline
\end{tabular}

\section{CONCLUSION}

The effect of workforce diversity taxonomy like diversity climate, value, organizational justice, and identity has been observed as significant on organizational culture and its factors. The results have shown that a perceived higher degree of diversity climate is the outcome of supportive policies and top management support, significantly influencing employees' autonomy in the high organizational concern. It is evident from the results that the faculty members who perceived high organizational justice significantly believed more in values, policies, procedures, transparency, decision making, etc. than their counterparts. The result interpreted that the employees with perceived in-group may enjoy more autonomy and freedom and select their method of work and experience responsibility in the organization compared to perceived out-group employees. Thus, the faculties of the in-group perceive a higher degree of openness in decision making, promotional awareness, and performance appraisal system.

In contrast, out-group members perceived less open decision-making and transparency in information sharing. The 
perceived high diversity climate, value, organizational justice, and in-group identity significantly influenced all mentioned factors of organizational culture except communication and interpersonal relations. Therefore, managing workforce diversity is vital for developing positive and strong organizational culture.

\section{LIMITATION AND STUDY FORWARD}

The current study analyzed workforce diversity with rich facets like diversity climate, value, organizational justice, and identity on organizational culture in higher education and universities of Pakistan. However, future studies can deploy the same measure on other sectors of the economy by adding more workforce diversity and organizational culture measures.

\section{RECOMMENDATIONS}

Based on the outcomes of this study, workforce diversity significantly influences organizational culture; therefore, the policymakers must concentrate on ensuring workforce diversity to improve an organizational culture that will help improve performance.

\section{AUTHORS' CONTRIBUTIONS:}

Aurangzeb: Data Analysis and its interpretation, Abstract and Conclusion writing.

Kamleshwer Lohana: Data Collection, working on literature, writing references, and after completion of research review the article.

Nazia Bibi: Data Collection, working on literature, writing references and after completion of research review the article

Ishtiaq ur Rehman: Data Collection, working on literature and after completing research, its review.

Shahida Habib Alizai: Data Collection, working on literature and after completing research, its review.

\section{REFERENCES}

1. Acquavita, S. P., Pittman, J., Gibbons, M., \& Castellanos-Brown, K. (2009). Personal and organizational diversity factors impact social workers' job satisfaction: Results from a national internet-based survey. Administration in Social Work, 33(2), 151-166. https://doi.org/10.1080/03643100902768824

2. Ali, M. (2016). Impact of gender-focused human resources management and performance: The mediating effects of gender diversity. Australian Journal of Management, 41: 376-97. https://doi.org/10.11 $77 / 0312896214565119$

3. Bana, W. M. (2016). Effect of organizational culture on workplace diversity in public universities in Kenya. International Journal of Education and Research, 4(8), 241-256.

4. Beytekin, O. F., Yalçınkaya, M., Doğan, M., \& Karakoç, N. (2010). The organizational culture at the university. The International Journal of Educational Researchers, 2(1), 1-13.

5. Bunderson, J. S., \& Sutcliffe, K. M. (2002). Comparing alternative conceptualizations of functional diversity in management teams: Process and performance effects. Academy of management journal, 45(5), 875-893. https://doi.org/10.2307/3069319

6. Cassar, V., \& Buttigieg, S. C. (2015). Psychological contract breach, organizational justice, and emotional well-being. Personnel Review, 25(2), 1051-1063. https://doi.org/10.1108/PR-04-2013-0061

7. Chin, Thoo Ai, and Huam Hon Tat. (2015). Does gender diversity moderate the relationship between supply chain management practice and performance in the electronic manufacturing service industry? International Journal of Logistic-Research and Application, 18, 35-45. https://doi.org/10.1080/13675567.2014.945399

8. Cho, S., \& Mor Barak, M. E. (2008). Understanding diversity and inclusion in a perceived homogeneous culture: A study of organizational commitment and job performance among Korean employees. Administration in Social Work, 32(4), 100-126. https://doi.org/10.1080/03643100802293865

9. Choi, Sungjoo, and Hall G. Rainey. (2010). Managing diversity in US Federal Agencies: Effects of Diversity Management on employee Perceptions of Organizational Performance. Public Administration Review, 70, 109-21. https://doi.org/10.1111/j.1540-6210.2009.02115.x

10. Drach-Zahavy, A., Somech, A., \& Trogan, R. (2013). Opposites Attract or Attack? Team Diversity, Diversity Climate, and Inter-Personal Aggression. In Academy of Management Proceedings, 13(1), 534-544. https://doi.org/10.5465/ambpp.2013.129

11. Fiske, S. T. (1998). Stereotyping, prejudice, and discrimination. The handbook of social psychology, 2(4), 357411.

12. Fra linger, B., \& Olson, V. (2007). Organizational culture at the university level: A study of the OCAI instrument. Journal of College Teaching \& Learning, 4(11), 85-97. https://doi.org/10.19030/tlc.v4i11.1528

13. Greenberg, J. (1990). Organizational justice: Yesterday, today, and tomorrow. Journal of Management, 16(2), 399-432. https://doi.org/10.1177/014920639001600208

14. Hashim, M., Ullah, M., Khan, M.A., (2017). Impact of time flexibility on employees' performance: A study of teaching faculty in government colleges of management sciences Peshawar. City University Research Journal, 
2(2), 34-47.

15. Hofhuis, J., Van Der Rijt, P. G., \& Vlug, M. (2016). Diversity climate enhances work outcomes through trust and openness in workgroup communication. Springer Plus, 5(1), 1-14. https://doi.org/10.1186/s40064-0162499-4

16. Hofhuis, J., van Der Zee, K. I., \& Otten, S. (2012). Social Identity Patterns in Culturally Diverse Organizations: The Role of Diversity Climate 1. Journal of applied social psychology, 42(4), 964-989. https://doi.org/10.1111/j.1559-1816.2011.00848.x

17. Hogg, M. A., \& Terry, D. I. (2000). Social identity and self-categorization processes in organizational contexts. Academy of management review, 25(1), 121-140. https://doi.org/10.5465/amr.2000.2791606

18. Khan, K. M., Ullah M. (2021). Mediating Role of Ethical Leadership Between Employees Empowerment and Competitive Edge: A Case of Commercial Banks in Pakistan. Humanities \& Social Sciences Reviews, 9(2), 219-231. https://doi.org/10.18510/hssr.2021.9223

19. Kossek, E. E., \& Zonia, S. C. (1993). Assessing diversity climate: A field study of reactions to employer efforts to promote diversity. Journal of organizational behaviour, 14(1), 61-81. https://doi.org/10.1002/ job.4030140107

20. Martins, E. C. and Terblanche, F. (2003). Building Organizational Culture that Stimulates Creativity and Innovation. European Journal of Innovation Management, 6(1): 64-74. https://doi.org/10.110 $\underline{8 / 14601060310456337}$

21. Pink-Harper, S. A., Davis, R. S., \& Burnside, R. (2017). "Justice for all”: An examination of self-identified LGBT job satisfaction in the US federal workforce. Canadian Journal of Administrative Sciences/Revue Comedienne des Sciences de administration, 34(2), 182-197. https://doi.org/10.1002/cjas.1420

22. Rastgar, A. A., \& Pourebrahimi, N. (2013). Social loafing in the banking industry of Iran: Investigating the role of organizational commitment. Asian Journal of Research in Social Sciences and Humanities, 3(5), 1-11.

23. Richard, Orlando C., Susan L. Kirby, and Ken Chadwick (2013). The impact of racial and gender diversity in management on financial performance: how participative strategy making features can unleash a diversity advantage. International Journal of Human Resources Management, 24, 2571-82. https://doi.org/10.1080/09 585192.2012.744335

24. Roman, M. (2017). Relationships between Women's Glass Ceiling Beliefs Career Advancement Satisfaction and Quit Intention. Walden Dissertations and Doctoral Studies, 3830, 1-149.

25. Schein, J. (2004). A field survey of factors affecting the adoption and perceived success of diversity training. Personnel Psychology, 48(2), 247-270. https://doi.org/10.1111/j.1744-6570.1995.tb01756.x

26. Talke, Katrin, Søren Salomo, and Alexander Kock. 2011. Top Management Team Diversity and Strategic Innovation Orientation: The Relationship and Consequences for Innovativeness and Performance. Journal of Product Innovation Management, 28, 819-32. https://doi.org/10.1111/j.1540-5885.2011.00851.x

27. Taye, M., Sang, G., \& Muthanna, A. (2019). Organizational culture and its influence on the performance of higher education institutions: The case of a state university in Beijing. International Journal of Research, 8(2), 77-90. https://doi.org/10.5861/ijrse.2019.3026

28. Taylor, A. S. (2011). Toward a Taxonomy of Diversity at Work: Developing and Validating the Workplace Diversity Inventory. Dissertations and Theses. Paper 158.

29. Thomas, Roosevelt R. (1990). From affirmative action to affirming diversity. Harvard Business Review, 68, 107-17.

30. Ullah, M., Malik., A.M., Zeb, A., Rehman, A. (2019). Mediating Role of Capital Structure between Corporate Governance and Risk. Journal of Managerial Sciences.13 (3), 47-56.

31. Ullah, M., Afghan, N., Afridi, A.S. (2019). Effects of Corporate Governance on Capital Structure and Financial Performance: Empirical Evidence from Listed Cement Corporations in Pakistan. Global Social Sciences Review. 4(3), 273-283. https://doi.org/10.31703/gssr.2019(IV-III).25

32. Van Knippenberg, Daan, Jeremy F. Dawson, Michael A. West, and Astrid C. Homan. (2011). Diversity faultiness, shared objectives, and top management team performance. Human Relations, 64, 307-36. https://doi.org/10.1177/0018726710378384

33. Wilder, C. P. M., Van den Berg, P. T., Gunk, U., Maslowski, R., \& Ashkanasy, N. (2001). On operationalizing organizational culture. In N. Ashkanasy (Chair), Beyond the handbook: Organizational culture in the twentyfirst century. Showcase symposium conducted at the Academy of Management Conference, Washington, DC, August. 